\title{
Effects of neutron irradiation on superconducting critical temperatures of in situ processed $\mathrm{MgB}_{2}$ superconductors
}

\author{
C.-J. Kim" ${ }^{*}$, S.-D. Park ${ }^{\mathrm{a}}$, B.-H. Jun ${ }^{\mathrm{a}}$, B. G. Kim ${ }^{\mathrm{b}}$, K.-N. Choo ${ }^{\mathrm{c}}$, and H.-C. Ri ${ }^{\mathrm{d}}$ \\ ${ }^{a}$ Neutron Science Division, Korea Atomic Energy Research Institute, Daejeon, Korea \\ ${ }^{\mathrm{b}}$ Neutron Utilization Technology Division, Korea Atomic Energy Research Institute, Daejeon, Korea \\ ${ }^{c}$ Advanced Nuclear Fuel Development Division, Korea Atomic Energy Research Institute, Daejeon, Korea \\ ${ }^{\mathrm{d}}$ Physics Department, Kyungpook National University, Daegu, Korea
}

(Received 5 February 2014; revised or reviewed 17 February 2014; accepted 18 February 2014)

\begin{abstract}
Effects of neutron irradiation on the superconducting properties of the undoped $\mathrm{MgB}_{2}$ and the carbon(C)-doped $M g B_{2}$ bulk superconductors, prepared by an in situ reaction process using $\mathrm{Mg}$ and $\mathrm{B}$ powder, were investigated. The prepared $\mathrm{MgB}_{2} \mathrm{samples}$ were neutron-irradiated at the neutron fluence of $10^{16}-10^{18} \mathrm{n} / \mathrm{cm}^{2}$ in a Hanaro nuclear reactor of KAERI involving both fast and thermal neutron. The magnetic moment-temperature (M-T) and magnetization-magnetic field (M-H) curves before/after irradiation were obtained using magnetic property measurement system (MPMS). The superconducting critical temperature $\left(T_{c}\right)$ and transition width were estimated from the M-T curves and critical current density $\left(J_{c}\right)$ was estimated from the M-H curves using a Bean's critical model. The $T_{c} \mathrm{~s}$ of the undoped $\mathrm{MgB}_{2}$ and C-doped $\mathrm{MgB}_{2}$ before irradiation were 36.9-37.0 K and 36.6-36.8 K, respectively. The $T_{c} \mathrm{~s}$ decreased to $33.2 \mathrm{~K}$ and $31.6 \mathrm{~K}$, respectively after irradiation at neutron fluence of $7.16 \times 10^{17} \mathrm{n} / \mathrm{cm}^{2}$, and decreased to 22.6 $\mathrm{K}$ and $24.0 \mathrm{~K}$, respectively, at $3.13 \times 10^{18} \mathrm{n} / \mathrm{cm}^{2}$. The $J_{c}$ cross-over was observed at the high magnetic field of $5.2 \mathrm{~T}$ for the undoped $\mathrm{MgB}_{2}$ irradiated at $7.16 \times 10^{17} \mathrm{n} / \mathrm{cm}^{2}$. The $T_{c}$ and $J_{c}$ variation after the neutron irradiation at various neutron fluences were explained in terms of the defect formation in the superconducting matrix by neutron irradiation.
\end{abstract}

Keywords: $\mathrm{MgB}_{2}$ superconductor, in situ process, carbon doping, neutron irradiation, superconducting temperature, critical current density

\section{1. 서 론}

초전도체의 산업응용을 위해 확보해야 할 두 가지 중요한 성질은 초전도 임계온도 $\left(T_{c}\right)$ 와 임계전류밀도 $\left(J_{c}\right)$ 다. $T_{c}$ 는 냉각매질의 종류를 결정한다. 현재 고자장 자석이나 의료용 $\mathrm{MRI}$ 초전도 자석에 사용되는 $\mathrm{NbTi}$ 초전도선재는 액체 헬륨으로 냉각한다. 액체 헬륨은 리터 당 가격이 2-3만원 정도 매우 고가이며, 지구상에서의 매장량이 한정적이다. 헬륨 가스는 유전이나 천연가스 매장지에 발견되며, 미국과 러시아 등 일부 국가에서만 생산되고 있다. 최근 중국과 신흥국가들의 경제성장과 세계 인구의 고령화로 인해 의료기 산업이 확대되고 있으며, 이에 따라 액체 헬륨의 수요가 급등하고 있다. 액체 헬륨의 수요-공급 불균형 현상으로 인해 헬륨의 가격이 상승함에 따라 일부 생산국에서는 자원의 무기화 전략으로 판매에 제한을 두고 있다.

2001년 일본에서 발견된 $\mathrm{MgB}_{2}$ 초전도체는 $T_{c}$ 가 $39 \mathrm{~K}$ 로, 화합물 초전도체 중 가장 높다[1]. $\mathrm{MgB}_{2}$ 는 액체헬륨을 사용하지 않고 냉동기만으로 냉각할 수 있는 장점이 있다. 또한 높은 $T_{c}$ 로 인해 초전도 기기의 냉각설계가 쉬어진다. $\mathrm{MgB}_{2}$ 를 선재형태로 가공해서 솔레노이드를 만들면 작동온도가 20-25 K인 초전도 자석을 제작할 수 있다[2]. 가까운 미래의 의료기 수요확대와 액체헬륨의 고갈을 고려할 때, 냉동기로 냉각하는 $\mathrm{MgB}_{2}$ 초전도 자석은 의료용 $\mathrm{MRI}$ 나 초전도 자석분야의 가장 가능성 있는 대안이 될 것이다. 초전도 전력분야에서는 한류기와 풍력발전기 등의 초전도 부품을 $\mathrm{MgB}_{2}$ 선재로 제작할 수 있다.

* Corresponding author: cjkim2@kaeri.re.kr
초전도의 산업화에 $T_{c}$ 와 더불어 중요한 성질은 $J_{c}$ 다. $\mathrm{MgB}_{2}$ 발견 초기에 $\mathrm{MgB}_{2}$ 의 $J_{c}$ 는 매우 낮았다. 이후 탄소나 탄소화합물의 첨가연구를 통해 $\mathrm{MgB}_{2}$ 의 $J_{c}$ 를 $\mathrm{NbTi}$ 을 대체할 수 있는 수준까지 향상시킬 수 있었다[3-7]. 현재 $\mathrm{MgB}_{2}$ 의 $J_{c}$ 수준으로 5 테스라(Tesla, T) 이상의 고자장에서의 활용은 어렵지만 1-3 T의 저자장에서의 활용은 가능할 것으로 예상된다[3].

초전도체에 전류가 흐르면 자체 자기장이 만들어 진다. 전류가 증가하면 내부에 형성되는 자기장도 커진다. 초전도 응용기기의 대부분이 고자기장 환경에 노출되어 있음을 고려한다면 자기장에 잘 견딜 수 있도록 재료의 미세조직을 설계해 주어야 한다. 자기장 환경에서 초전도체에 많은 전류를 흘리려면 재료내부에 자기장을 잡아주는 자기속박점(Flux pinning center)을 만들어 주어야 한다. 초전도체 내부에서 움직이는 자속(Flux)은 비초전도 상태의 결함들에 의해 속박된다. 자기속박점으로 작용할 수 있는 결함의 크기는 초전도체에서 쿠퍼(Cooper) 전자쌍을 형성하는 결맞음 길이(Coherence length)와 관계가 있다[8]. 고온 산화물 초전도체의 경우는 결정입계가 약하게 결합되어 있고, 결맞음 길이가 짧아 나노미터 크기의 결함(YBCO의 경우 2-4 nm)이라야 자기속박력을 갖는다 [8]. 반면에 $\mathrm{MgB}_{2}$ 와 같이 전류 이방성이 작고, 결맞음 길이가 큰 재료는 결정입계가 자기속박점으로 작용하기 때문에 불순물 입자를 첨가하는 화학적 도핑[3-6]이나 결정 미세화[6]와 같은 공정으로 자기속박 특성을 제어할 수 있다. 화학적 도핑과 더불어 초전도 내부에 효과적으로 결함을 생성하는 방법은 중이온[9,10]이나 중성자 조사[11-17]와 같은 물리적 방법이다. 이온이나 전자빔 조사는 빔의 침투 깊이가 짧기 때문에 결함이 주로 시료의 표면에서 
생성되지만 중성자 조사는 중성자 침투 깊이가 깊기 때문에 결함들이 시편 내부까지 균일하게 생성된다. 또한 조사 에너지의 수준에 따라 점 결함(Vacancy)과 같은 미세결함에서 기공(Void)까지 다양한 결함이 생성된다.

본 연구에서는 $\mathrm{MgB}_{2}$ 에 대한 중성자 조사효과를 알고자 한국원자력연구원의 하나로 연구용 원자로 조사시설을 이용하여 $\mathrm{MgB}_{2}$ 에 대해 중성자 조사를 실시하였다. 시료로 마그네슘과 보론 분말을 원료로 사용하여 반응공정으로 제조한 $\mathrm{MgB}_{2}$ 를 사용하였으며, 중성자 조사의 $T_{c}$ 와 $J_{c}$ 에 대한 영향을 조사하였다.

\section{2. 실험방법}

\section{1. $\mathrm{MgB}_{2}$ 시편 제조와 물성 측정}

마그네슘 $(\mathrm{Mg}$, 순도 $99.7 \%$, 입도 4-6 $\mu \mathrm{m}$, Tangshan Weihao Co. Ltd., China)과 보론(B, 순도 95-97\%, 입도 $1 \mu \mathrm{m}$ 이하, Tangshan Weihao Co. Ltd., China) 분말을 원료로 사용하였다. $\mathrm{MgB}_{2}$ 의 $J_{c}$ 를 높이기 위해서는 작은 크기의 보론 분말을 사용해야 한다. 보론 분말을 분쇄하고자 톨루엔 $\left(\mathrm{C}_{7} \mathrm{H}_{8}\right.$, $99.5 \%$ ) 용매에 보론 분말을 넣고 $2 \mathrm{~mm}$ 지름의 지르코니아 $\left(\mathrm{ZrO}_{2}\right)$ 볼을 사용하여 $200 \mathrm{rpm}, 2$ 시간 동안 밀링한 다음, $100^{\circ} \mathrm{C}$ 진공오븐에서 건조하였다. 준비된 보론 분말을 $\mathrm{Mg}: \mathrm{B}=1: 2$ 의 비로 $\mathrm{Mg}$ 분말과 혼합하였다. 혼합분말을 스틸(Steel) 몰드에서 가압성형법으로 직경 $15 \mathrm{~mm}$, 두께 1.2 $\mathrm{mm}$ 펠렛으로 제조 후, 타이타늄(Ti) 튜브에 넣어 고순도 $\mathrm{Ar}$ 분위기에서 승온속도 $5^{\circ} \mathrm{C} / \mathrm{min}$ 로 $850^{\circ} \mathrm{C}$ 까지 가열하여 30 분간 유지하였다. 글리세린 처리한 보론 분말[6]을 사용하여 탄소를 도핑한 $\mathrm{MgB}_{2}$ 를 제작하였다. 밀링된 보론 분말은 탄소 소스인 글리세린을 첨가하여 $40^{\circ} \mathrm{C}$ 에서 적당시간 유지한 다음, $200^{\circ} \mathrm{C}$ 에서 20 시간 동안 진공오븐에서 건조하였다. 보론을 글리세린 처리하면 탄소가 첨가되는 이유는 이전의 연구결과[6,7]에 자세히 기록되어 있다. $\mathrm{MgB}_{2}$ 에 탄소 도핑은 초전도체의 $J_{c}$ 를 향상[5]시킨다고 알려져 있기 때문에 탄소를 첨가한 시편을 제작해서 실험에 사용하였다.

그림 1 은 분말반응법으로 제조한 $\mathrm{MgB}_{2}$ 펠렛의 사진이다. 상 분석을 위해 시편을 분쇄해서 분말 $\mathrm{X}$-선법으로 분석한 결과, $\mathrm{MgB}_{2}$ 상이 잘 생성되었음을 확인하였다. 이 디스크 형 펠렛을 한 변의 길이가 수 $\mathrm{mm}$ 인 사각시편으로 절단하여 중성자 조사용 시편으로 사용하였다.

중성자 조사 전과 후 시편에 대해 $T_{c}$ 와 $J_{c}$ 를 최대 인가자기장이 9 T인 Material Property Measurement System (MPMS, Quantum Design)를 사용해서 측정하였다. $T_{c}$ 는 온도-자화율 곡선에서 초전도가 시작되는 온도를 기준으로 했다. 시편의 $J_{c}$ 는 일정온도에서의 측정된 자장-자화율 결과에 Bean critical model[18]을 적용하여 계산하였다.

\section{2. 중성자 조사 시험}

$\mathrm{MgB}_{2}$ 에 대한 중성자조사효과를 알아보고자 한국원자력연구원 하나로 원자로에서 중성자 조사를 실시하였다. 조사시편에 대한 이력(시편의 조성, 중량과 치수)과 조사조건(조사시간, 조사선량과 잔류방사선량)을 표 I에 요약하였다. 하나로 조사공에 시편을 위치시킨 후에 조사시간을 달리해서 $10^{16}-10^{18} \mathrm{n} / \mathrm{cm}^{2}$ 구간에서 조사선량을 변화시켰다. 하나로 조사시설에는 열중성자를 차단하는 장치가 설치되어 있지 않기 때문에 조사에 사용된 중성자 선원은 소속중성자와 열중성자 모두를 포함한다. 중성자

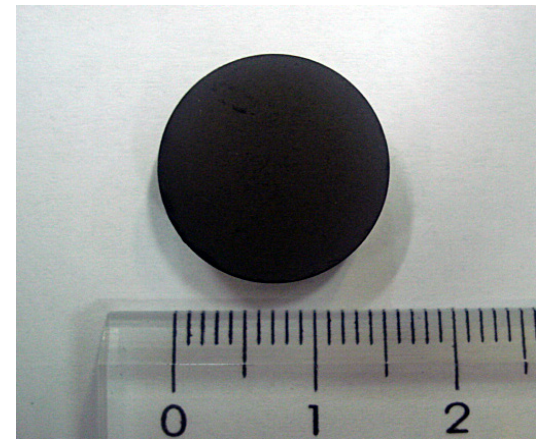

Fig. 1. $\mathrm{MgB}_{2}$ pellet prepared using an in situ reaction process using $\mathrm{Mg}$ and $\mathrm{B}$ powder.

TABLE I

SPECIFICATION OF $\mathrm{MgB}_{2}$ SAMPLES USED FOR NEUTRON IRRADIATION EXPERIMENT AND IRRADIATION CONDITION.

\begin{tabular}{cccccc}
\hline Sample & $\begin{array}{c}\text { Weight } \\
(\mathrm{mg})\end{array}$ & $\begin{array}{c}\text { Dimension } \\
\left(\mathrm{mm}^{3}\right)\end{array}$ & $\begin{array}{c}\text { Irradiatio } \\
\mathrm{n} \text { time } \\
(\mathrm{min})\end{array}$ & $\begin{array}{c}\text { Neutron } \\
\text { fluence } \\
\left(\mathrm{n} / \mathrm{cm}^{2}\right)\end{array}$ & $\begin{array}{c}\text { Residual } \\
\text { Radioacti } \\
\text { vity } \\
(\mathrm{nSv} / \mathrm{h})\end{array}$ \\
\hline C-doped $\mathrm{MgB}_{2}$ & 5.2 & $0.83 \times 1.67 \times 2.76$ & 60 & $1.13 \times 10^{17}$ & 313 \\
$\mathrm{C}$-doped $\mathrm{MgB}_{2}$ & 1.9 & $0.82 \times 0.86 \times 1.90$ & 60 & $1.13 \times 10^{17}$ & 370 \\
Undoped $\mathrm{MgB}_{2}$ & 5.1 & $1.14 \times 1.27 \times 2.55$ & 380 & $7.16 \times 10^{17}$ & 521 \\
Undoped $\mathrm{MgB}_{2}$ & 4.1 & $1.10 \times 1.27 \times 2.08$ & 380 & $7.16 \times 10^{17}$ & 402 \\
C-doped $\mathrm{MgB}_{2}$ & 4.1 & $0.92 \times 1.48 \times 2.27$ & 380 & $7.16 \times 10^{17}$ & 330 \\
C-doped $\mathrm{MgB}_{2}$ & 2.5 & $0.87 \times 1.20 \times 1.93$ & 380 & $7.16 \times 10^{17}$ & 300 \\
Undoped $\mathrm{MgB}_{2}$ & 4.6 & $0.94 \times 1.06 \times 3.57$ & 1660 & $3.13 \times 10^{18}$ & 795 \\
Undoped $\mathrm{MgB}_{2}$ & 3.2 & $0.97 \times 1.12 \times 2.06$ & 1660 & $3.13 \times 10^{18}$ & 833 \\
C-doped $\mathrm{MgB}_{2}$ & 4.1 & $1.05 \times 1.38 \times 2.09$ & 1660 & $3.13 \times 10^{18}$ & 760 \\
C-doped $\mathrm{MgB}_{2}$ & 3.3 & $1.01 \times 1.34 \times 1.79$ & 1660 & $3.13 \times 10^{18}$ & 870 \\
\hline
\end{tabular}

조사로 인한 방사화로 반감기가 긴 핵 종이 생성되어 조사 후에 곧바로 이송하지 못한 시편들은 방사선량이 감소할 때까지 로내의 시설에서 장시간 유지하였다. 일정시간이 지난 후, 잔류 방사선량이 외부로 방출이 가능한 수준인 시편에 대해서만 초전도 특성을 측정하였다. 예를 들어, 표 I에서 잔류방사선량이 $800 \mathrm{nSv} / \mathrm{h}$ 이상인 몇몇의 시편들에 대해서는 물성측정을 수행하지 못했다. 측정시편은 방사선 오염을 방지하고자 석영관에 넣었다.

\section{3. 결과 및 고찰}

그림 2(a)와 2(b)는 중성자 조사 전의 undoped $\mathrm{MgB}_{2}$ 와 $\mathrm{C}$-첨가 $\mathrm{MgB}_{2}$ 의 자기모멘트-온도 곡선이다. 두 시료의 $T_{c}$ 는 각각 $36.8 \mathrm{~K}$ 와 $36.6 \mathrm{~K}$ 이다. $37 \mathrm{~K}$ 부근에서 초전도전이는 전위 폭이 대략 $1 \mathrm{~K}$ 정도로 매우 급격하다. 이는 제조된 시편들에 $T_{c}$ 가 동일한 초전도 상이 매우 균일하게 분포하고 있음을 의미한다.

일반적으로 $99.9 \%$ 이상 순도분말을 원료로 사용하여 $\mathrm{MgB}_{2}$ 를 제조하면 $T_{c}$ 는 $39 \mathrm{~K}$ 가 되는 것으로 보고되어 있다[1] 본 실험에서는 원료분말인 $\mathrm{Mg}$ 와 $\mathrm{B}$ 을 각각 $99 \%$ 와 $97 \%$ 순도의 것을 사용하였기 때문에 불순물의 영향으로 $T_{c}$ 가 낮다. 저순도의 분말을 사용해서 시료를 만든 이유는 초전도체의 산업화를 목적으로 원료의 단가를 낮추기 위해서였다. 

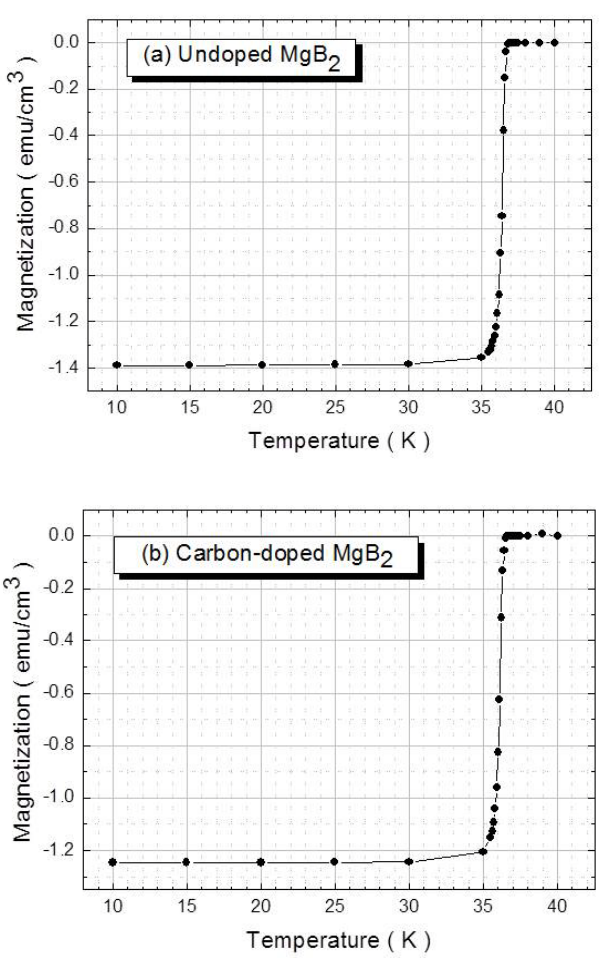

Fig. 2. Magnetic moment-temperature curves of (a) undoped $\mathrm{MgB}_{2}$ and (b) C-doped $\mathrm{MgB}_{2}$ before irradiation.

그림 3은 중성자 조사 후에 측정한 자화율-온도 곡선의 대표적인 예시로, 탄소를 첨가한 $\mathrm{MgB}_{2}$ 시편에 대한 결과이다. 이 시편의 중성자 조사 전의 $T_{c}$ 는 $36.6 \mathrm{~K}$ 이었다. 그림에서 알 수 있는 것처럼, $7.17 \times 10^{17} \mathrm{n} / \mathrm{cm}^{2}$ 의 조사선량에서 조사했을 때 시편의 $T_{c}$ 는 $31.6 \mathrm{~K}$ 로, $5 \mathrm{~K}$ 정도 감소한다. $T_{c}$ 감소와 더불어 초전도 전위 폭이 커진다. 이 시편의 초전도 전위 폭은 $10 \mathrm{~K}$ 정도로, 조사전의 전위폭 값인 $1 \mathrm{~K}$ 에 비해 상대적으로 크다. 만일, 중성자 조사에 의해 초전도온도가 감소하더라도 조사에 의해 생성된 상들이 $T_{c}$ 가 같고 시편내부에 균일하게 존재한다면 초전도 전이는 특정온도에서 급격하게 이루어질 것이다. 중성자 조사에 의해 초전도체 내부에 결함이 생성되고[12,17], 이 결함의 농도와 격자의 규칙성에 의해 $T_{c}$ 가 결정된다고 가정할 때 초전도 전위폭이 커진 결과는 중성자 조사에 의해 시편내부에 $T_{c}$ 가 다른 상들이 생성됨을 의미한다.

중성자 조사 전후에 시편들에 대해 측정된 자화율-온도 결과로부터 얻은 $T_{c}$ 변화를 표 II에 요약하였다. 표에서 알 수 있듯이, $7.16 \times 10^{17} \mathrm{n} / \mathrm{cm}^{2}$ 조사선량에 대한 undoped $\mathrm{MgB}_{2}$ 의 조사 전의 $T_{c}$ 는 $37 \mathrm{~K}$ 이었다. 조사 후의 $T_{c} 33.2 \mathrm{~K}$ 로 $T_{c}$ 감소는 $3.8 \mathrm{~K}$ 이다. 동일한 조사선량에 대해 $T_{c}$ 의 감소폭은 탄소를 첨가한 $\mathrm{MgB}_{2}$ 가 undoped $\mathrm{MgB}_{2}$ 보다 상대적으로 크다. 조사선량 $3.13 \times 10^{18} \mathrm{n} / \mathrm{cm}^{2}$ 에 대해 두 시편의 조사 전의 $T_{c}$ 는 각각 $36.9 \mathrm{~K}$ 와 $36.8 \mathrm{~K}$ 로 거의 같다. 조사 후의 $T_{c}$ 는 각각 22.6 $\mathrm{K}$ 와 $24 \mathrm{~K}$ 로, 조사선량 증가에 따라 $T_{c}$ 감소폭이 각각 14.3 $\mathrm{K}$ 와 $12.8 \mathrm{~K}$ 이다. 이 중성자 조사 선량에서는 탄소를 첨가한 시편의 $T_{c}$ 감소가 undoped $\mathrm{MgB}_{2}$ 보다 상대적으로 적다. 이는 중성자 조사공의 위치에 따라서 중성자속이 다소 다를 수 있기 때문에 발생하는 차이로 여겨진다. 이와 같은 $T_{c}$ 감소폭의 조사선량 의존성은 조사선량이 증가할수록 초전도체의 결정구조가 받는 손상의 정도가 증가하고 있음을 의미한다.

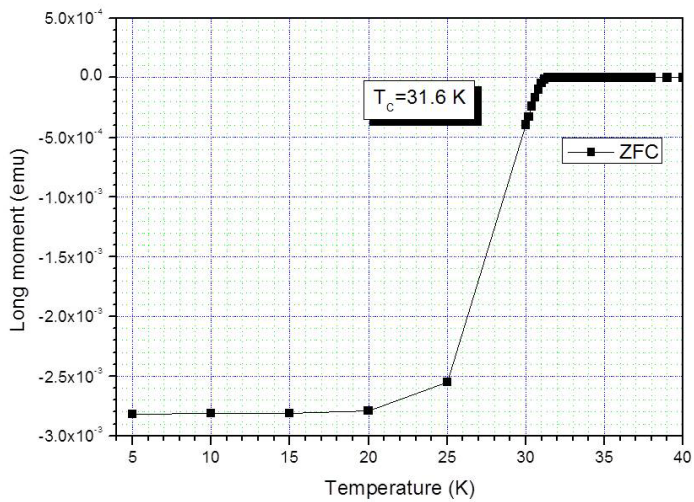

Fig. 3. Magnetization-temperature curve of the C-doped $\mathrm{MgB}_{2}$ after irradiation at a neutron fluence of $7.17 \times 10^{17}$ $\mathrm{n} / \mathrm{cm}^{2}$.

$\mathrm{Pb}$ 가 첨가된 $\mathrm{BiSrCaCuO}$ 에 대한 중성자 조사 연구[11]에 의하면, 중성자 조사에 의해 $T_{c}$ 가 감소했으며, 감소 정도는 중성자속과 비례했다. 이 데이타는 한국원자력연구원 TRIGA MARK III 연구로에서 수행된 연구결과로, 조사조건이 본 연구와 거의 동일하였다. 하나로 조사시설에는 열중성자를 차단하는 시설이 없기 때문에 실험에 사용된 중성자 조사선원은 고속중성자와 열중성자 모두를 포함하고 있다. 따라서 본 연구에서 관찰된 중성자 조사에 의한 $T_{c}$ 감소는 열중성자와 고속 중성자에 의한 격자이동이나 결함생성에 따른 것이라 할 수 있다. 또한 조사 전 $T_{c}$ 가 $39.1 \mathrm{~K}$ 인 $\mathrm{MgB}_{2}$ 에 대해 중성자속 $2.0 \times 10^{18} \mathrm{n} / \mathrm{cm}^{2}$ 으로 조사한 연구결과[15]에 따르면, $T_{c}$ 가 $33.3 \mathrm{~K}$ 로 $5.8 \mathrm{~K}$ 감소했고, 중성자속이 더 커지면 $T_{c}$ 는 매우 급격히 감소하였다. 또한 $T_{c}$ 가 $91 \mathrm{~K}$ 인 단결정 $\mathrm{YBa}_{2} \mathrm{Cu}_{3} \mathrm{O}_{7-\mathrm{y}}$ 시료에 대해서 중성자속 $1.0 \times 10^{18} \mathrm{n} / \mathrm{cm}^{2}$ 로 조사 실험을 한 연구에서는 $T_{c}$ 는 $86.5 \mathrm{~K}$ 로 감소하였다[12,13]. 다결정 $\mathrm{YBa}_{2} \mathrm{Cu}_{3} \mathrm{O}_{7-\mathrm{y}}$ 시편에 대한 고속 중성자 조사 실험에서도 $T_{c}$ 는 감소하였으며, $T_{c}$ 감소 정도는 중성자속에 비례했다[14]. 이 결과들은 본 실험에서 얻은 결과와 잘 일치한다.

중성자조사에 의한 초전도체의 $T_{c}$ 감소는 매우 일반적인 현상으로 조사에 의한 결함생성과 격자변형과 관련이 있다. 중성자조사로 초전도체 내부에 결함이 생성되고 이에 따라 $T_{c}$ 가 감소하지만 결함생성은 초전도체의 전류특성 향상에 도움이 된다. 미세한 결함들은 자기속박점으로 작용해서 초전도체 내부로 흐르는 전류의 양을 증가시킬 수 있기 때문이다[8]. $\quad T_{c}$ 가 약간 감소하더라도 전류밀도가 증가한다면 $J_{c}$ 관점에서는 중성자 조사의 효과를 얻었다고 할 수 있다.

TABLE II

VARIATION OF $T_{c}$ OF $\mathrm{MgB}_{2}$ AFTER NEUTRON IRRADIATION AT VARIOUS NEUTRON FLUENCES.

\begin{tabular}{|c|c|c|c|c|c|}
\hline \multirow[b]{2}{*}{ Sample } & \multirow[b]{2}{*}{$\begin{array}{l}\text { Dimension } \\
\left(\mathrm{mm}^{3}\right)\end{array}$} & \multirow[b]{2}{*}{$\begin{array}{l}\text { Neutron } \\
\text { fluence } \\
\left(\mathrm{n} / \mathrm{cm}^{2}\right)\end{array}$} & \multicolumn{2}{|c|}{ Critical temperature (K) } & \multirow[b]{2}{*}{$\begin{array}{c}\left(\mathrm{T}_{\text {onset, } \mathrm{b}^{-}}\right. \\
\left.\mathrm{T}_{\text {onset, }, \mathrm{a}}\right)\end{array}$} \\
\hline & & & $\begin{array}{c}\text { Before } \\
\text { irradiation } \\
\left(\mathrm{T}_{\text {onset, }}\right) \\
\end{array}$ & $\begin{array}{c}\text { After } \\
\text { irradiation } \\
\left(\mathrm{T}_{\text {onset, },}\right) \\
\end{array}$ & \\
\hline $\begin{array}{c}\text { C-doped } \\
\mathrm{MgB}_{2}\end{array}$ & $0.82 \times 0.86 \times 1.90$ & $1.13 \times 10^{17}$ & 36.6 & 33.5 & 3.1 \\
\hline $\begin{array}{c}\text { Undoped } \\
\mathrm{MgB}_{2}\end{array}$ & $1.14 \times 1.27 \times 2.55$ & $7.16 \times 10^{17}$ & 37.0 & 33.2 & 3.8 \\
\hline $\begin{array}{c}\text { C-doped } \\
\mathrm{MgB}_{2}\end{array}$ & $0.92 \times 1.48 \times 2.27$ & $7.16 \times 10^{17}$ & 36.6 & 31.6 & 5.0 \\
\hline $\begin{array}{c}\text { Undoped } \\
\mathrm{MgB}_{2}\end{array}$ & $0.94 \times 1.06 \times 3.57$ & $3.13 \times 10^{18}$ & 36.9 & 22.6 & 14.3 \\
\hline $\begin{array}{c}\text { C-doped } \\
\mathrm{MgB}_{2}\end{array}$ & $1.05 \times 1.38 \times 2.09$ & $3.13 \times 10^{18}$ & 36.8 & 24.0 & 12.8 \\
\hline
\end{tabular}




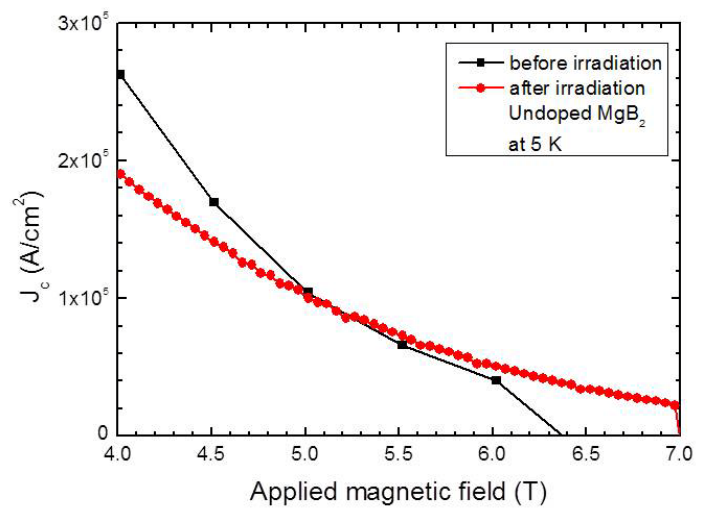

Fig. 4. $J_{c}-B$ curves of the undoped $\mathrm{MgB}_{2}$ sample before/after neutron irradiation at neutron fluence of $7.17 \times 10^{17} \mathrm{n} / \mathrm{cm}^{2}$.

이미 전술한 바와 같이, 본 연구에서의 중성자를 조사한 시 료들에서 반감기가 긴 핵종이 발생하였기 때문에 방사선 안 전상의 이유로 시료를 석영관에 밀봉한 후 자기이력곡선을 측정하였다. 석영관 내부에 위치한 시료들은 중성자 조사 전 에 실시한 실험과 같이 시료를 자기장에 정확히 정렬할 수 없 기 때문에 중성자 조사 이후의 임계전류밀도를 정확히 계산 할 수는 없었지만, 그림 4의 결과로부터 결함생성의 임계전 류에 대한 영향을 어느 정도 추측할 수 있었다.

그림 4의 undoped $\mathrm{MgB}_{2}$ 시료에 대한 중성자 조사 전후의 5 $\mathrm{K}$ 에서의 $J_{c}-B$ 곡선을 보면 저자장 영역에서는 조사 전의 $J_{c}$ 가 조사 후의 $J_{c}$ 보다 크다. 자장이 증가해서 $5.2 \mathrm{~T}$ 가 되면 조 사전과 후의 $J_{c}$ 가 같아지고, 그 이상의 자장에서는 조사 후의 $J_{c}$ 가 조사전보다 더 높은 $J_{c}$ 역전(Cross-over)이 관찰된다. $\mathrm{MgB}_{2}$ 에 대해 중성자 조사를 수행한 다른 연구보고[15-17]에 따르면, 단결정 $\mathrm{MgB}_{2}$ 에 대한 중성자 조사효과는 자장이 증 가할 때 $J_{c}$ 가 비이상적으로 높아지는 물고기 꼬리(Fishtail) 현상이 나타났다[17]. 또한 보론 동위원소 $\left(\mathrm{B}^{11}\right)$ 을 사용해서 제조한 $\mathrm{MgB}_{2}$ 다결정의 경우도 중간 자기장 영역에서 $J_{c}$ 가 최 대가 되는 피크(Peak) 효과로 나타났다 $[15,16]$. 이 결과들은 중성자 조사에 의해 생성된 결함이 강한 자기속박력을 가짐 을 의미한다. 본 연구에 사용된 다결정 $\mathrm{MgB}_{2}$ 는 $\mathrm{B}^{10}$ 이 많이 포 함된 물질로, 다른 연구 결과에서 사용된 $\mathrm{MgB}_{2}$ 의 결정성이 나 보론의 중성자 흡수단면적이 다르기 때문에 직접 비교할 수는 없지만 중성자 조사에 따른 $J_{c}$ 의 증가 효과는 존재한다 고 할 수 있다.

앞으로는 중성자 조사에 따른 초전도체 내부에서의 결함 생성기구의 이해, 초전도체의 전류특성 향상을 위한 적정수 준의 중성자 조사 조건과 중성자 조사기술의 산업화를 위해 방사능 핵종의 생성 억제 등에 대한 연구가 진행되어야 할 것 이다.

\section{4. 결 론}

분말반응법으로 제조한 두 종류의 다결정 시료 (Undoped $\mathrm{MgB}_{2}$ 와 C-doped $\mathrm{MgB}_{2}$ )에 대해 중성자속 $10^{16}-10^{18} \mathrm{n} / \mathrm{cm}^{2}$ 조건에서 중성자 조사를 수행하였다. 두 시편의 조사전의 $T_{c}$ 는 각각 $36.9-37 \mathrm{~K}$ 와 $36.6-36.8 \mathrm{~K}$ 이었다. 중성자 조사 효과는 $T_{c}$ 의 감소로 나타났다. 또한 $T_{c}$ 는 중성자속에 비례해서 감소했다. 중성자속 $10^{17} \mathrm{n} / \mathrm{cm}^{2}$ 에서는 $T_{c}$ 감소가 수 $\mathrm{K}$ 정도이지만 $10^{18} \mathrm{n} / \mathrm{cm}^{2}$ 이상에서는 $T_{c}$ 감소가 $12-14 \mathrm{~K}$ 로 매우 컸다. 중성자조사에 따른 $T_{c}$ 의 변화는 탄소를 첨가한
시편에서도 동일하게 관찰되었으며, 그 경향도 유사했다. 중성자 조사에 의한 $T_{c}$ 의 감소는 중성자에 의한 초전도 격자의 손상과 결함생성에 의한 것으로 여겨진다. 중성자 조사는 $\mathrm{MgB}_{2}$ 의 $T_{c}$ 의 감소뿐 아니라 초전도 전이폭의 확대를 초래한다. 이는 조사에 의해 초전도체 내부에 넓은 영역의 $T_{c}$ 를 갖는 상들이 생성됨을 의미한다. 중성자 조사는 $T_{c}$ 뿐만 아니라 $\mathrm{MgB}_{2}$ 의 $J_{c}$ 에도 영향을 준다. 중성자속 $7.16 \times 10^{17}$ $\mathrm{n} / \mathrm{cm}^{2}$ 에서 조사된 undoped $\mathrm{MgB}_{2}$ 의 $J_{c}$ 는 저자장에서는 조사전보다 작지만 $5.2 \mathrm{~T}$ 이상에서는 조사전의 $J_{c}$ 보다 컸다. 이는 중성자 조사로 인해 결함이 생성되고, 이들이 자속 고정점으로 작용하였기 때문이다. 본 연구결과는 재료내의 미세결함의 농도에 따라 물성이 변하는 초전도나 전자기 신물질 연구에 중성자 조사기술이 효과적으로 사용될 수 있음을 의미한다.

\section{ACKNOWLEDGMENT}

이 연구는 2013년 미래창조과학부의 재원의 지원을 받아 연구재단의 과제로 수행되었음을 밝힙니다 (과제번호 NRF-2013M2A8A1035822).

\section{REFERENCES}

[1] J. Nagamatsu, N. Nakagawa, T. Muranka, Y. Zenitanium, J Akimitsu, "Superconductivity at $37 \mathrm{~K}$ in Magnesium Diborade," Nature (London), vol. 410, pp. 63-65, 2001.

[2] R. Musenich, P. Fabbricatore, S. Farinon, M.Greco, M. Modica, R. Marabotto, R. Penco, M. Razeti, D.Nardelli, "The behaviour of cryogen-free $\mathrm{MgB}_{2}$ react and wind coils," Supercond. Sci. Technol., vol. 19, pp. S126-S131, 2006.

[3] K. Vinod, R. G. Abhilash Kumar and U. Syamaprasad, "Prospects for $\mathrm{MgB}_{2}$ superconductors for magnet application," Supercond. Sci. Technol., vol. 20, pp. R1-R13, 2007.

[4] S. X. Dou, S. Soltanian, J. Horvat, X. L. Wang, S. H. Zhou, M. Ionescu, and H. K. Liu, P. Munroe, M. Tomsic, "Enhancement of the critical current density and flux pinning of $\mathrm{MgB}_{2}$ superconductor by nanoparticle SiC doping," Appl. Phys. Lett., vol. 81, No. 18, pp. 3419-3421, 2002.

[5] J. H. Kim, S. Zhou, M. S. A. Hossain, A. V. Pan, and S. X. Dou, "Carbohydrate doping to enhance electromagnetic properties of $\mathrm{MgB}_{2}$ Superconductors" Appl. Phys. Lett., vol. 89, 142505 (3pp), 2006.

[6] B.-H. Jun, Y.-J. Kim, K. S. Tan and C.-J. Kim, "Effective carbon incorporation in $\mathrm{MgB}_{2}$ by combining mechanical milling and the glycerin treatment of boron powder," Supercond. Sci. Technol., vol. 21, 105006 (5pp), 2008.

[7] Y. J. Kim, B.-H. Jun, K. S. Tan, B. G. Kim, J. M. Sohn, C.-J. Kim, "Effect of glycerin addition on the superconducting properties of $\mathrm{MgB}_{2}$," Physica C, vol. 468, Issue 15-20, pp. 1372-1374, 2008

[8] T. Haugan, P. N. Barnes, R. Wheeler, F. Meisenkothen, M. Sumption, "Addition of nanoparticle dispersions to enhance flux pinning of the $\mathrm{YBa}_{2} \mathrm{Cu}_{3} \mathrm{O}_{7-\mathrm{x}}$ superconductor," Nature, vol. 430, pp. 867-870, 2004.

[9] M. Haruta, T. Fujiyoshi, T. Sueyoshi, K. Miyahara, T, Ikegami, K. Ebihara, R. Miyagawa, N. Ishikawa, S. Awaji, k. Watanabe, "Influence of columnar defects on pinning parameters in high- $\mathrm{T}_{\mathrm{c}}$ superconductors", Physica C, vol. 412-414, pp. 511-514, 2004.

[10] D. Behera, T. Mohanty, S.K. Dash, T. Banerjee, D. Kanjilal, N.C. Mishra, "Effect of secondary electrons from latent tracks created in YBCO by swift heavy ion irradiation", Radiation measurement, vol. 36, pp. 125-129, 2003.

[11] Y.H. Herr, K.-H. Lee, C.-J. Kim, H.-G. Lee, C.-T. Kim, G.-W. Hong, D.-Y. Won, "Effect of neutron irradiation on $\mathrm{T}_{\mathrm{c}}$ of Pb-doped BiSrCaCuO superconductor," Jpn. J. Appl. Phys., vol. 28, No. 9, L1561-L1563, 1989. 
[12] F. W. Sauerzipf, H. P. Wiesinger, and H. W. Weber, "Analysis of pinning effects in $\mathrm{YBa}_{2} \mathrm{Cu}_{3} \mathrm{O}_{7-\mathrm{d}}$ single crystals after fast neutron irradiation," Phys. Rev. B, vol. 51, pp. 6002-6012, 1995.

[13] A. Umezawa et al, "Enhanced crystal magnetization currents due to fast neutron irradiation in single-crystal $\mathrm{YBa}_{2} \mathrm{Cu}_{3} \mathrm{O}_{7-\mathrm{d}}$," Phys. Rev. $B$, vol. 36, No. 13, pp. 7151-7154, 1987.

[14] J. R. Cost, J. O . Willis, J. D. Thomson, and D. E. Peterson, "Fast-neutron irradiation of $\mathrm{YBa}_{2} \mathrm{Cu}_{3} \mathrm{O}_{\mathrm{x}}$ " Phys. Rev. B, vol. 37, pp. 1563-1568, 1988

[15] C. Tarantini et al, "Effects of neutron irradiation on polycrystalline $\mathrm{Mg}^{11} \mathrm{~B}_{2}$," Phys. Rev. B, vol. 73, 134518(11pp), 2006.
[16] M. Putti et al, "Neutron irradiation of $\mathrm{Mg}^{11} \mathrm{~B}_{2}$ : From the enhancement to the suppression of superconducting properties," Appl. Phys. Lett., vol. 86 112503(3pp), 2005.

[17] M. Zehetmayer et al, "Fishtail effect in neutron-irradiated superconducting $\mathrm{MgB}_{2}$ single crystals," Phys. Rev. B, vol. 69, 054510 (7pp), 2004

[18] C. P. Bean, "Magnetization of Hard Superconductors," Phys. Rev. Lett. vol. 8, Issue 6, pp. 250-253 1962. 